\title{
LITERATURE REVIEW : PERANCANGAN TRACER DALAM PENYIMPANAN DOKUMEN REKAM MEDIS
}

\author{
Riya Ismawati ${ }^{1}$, Rohmadi $^{2}$ \\ riyaismawati28@gmail.com, rohmadi@stikesmhk.ac.id
}

\begin{abstract}
Tracer Medical recordis a tool used to control the use of medical record documents which are usually used to replace medical record documents that come out of storage shelves. Problems that occur in the storage system are misfiles and delays in returning medical record documents anddesigns tracer that are not up to standard. The method used is a literature review to determine thedesign tracer based on aspects of size, material and color, content, pouch and request slip. It was concluded that the size used was in accordance with the standard, which was equal to or larger than the medical record, the material used was strong and brightly colored so that it was easy to search, contained the contents of the patient's name, medical record number, the purpose of the medical record or borrower and the date of discharge and there was a pocket. and the request slip on the tracer.
\end{abstract}

Keywords : tracer, design, medical record

\begin{abstract}
Abstrak
Tracer rekam medis adalah sarana yang digunakan untuk mengontrol penggunaan dokumen rekam medis yang biasanya digunakan untuk menggantikan dokumen rekam medis yang keluar dari rak penyimpanan. Permasalah yang terjadi pada sistem penyimpanan yaitu misfile dan keterlambatan pengembalian dokumen rekam medis serta rancangan tracer yang tidak sesuai standar. Metode yang digunakan adalah literature review untuk mengetahui rancangan tracer berdasarkan aspek ukuran, bahan dan warna, isi, kantong dan slip permintaan. Didapatkan kesimpulan ukuran yang digunakan sudah sesuai standar yaitu sama atau lebih besar dari rekam medis, bahan yang digunakan kuat dan berwarna mencolok agar mudah dalam pencarian, memuat isi berupa nama pasien,nomor rekam medis,tujuan rekam medis atau peminjam dan tanggal keluar serta terdapat kantong dan slip permintaan pada tracer tersebut.
\end{abstract}

Kata Kunci : tracer,perancangan,rekam medis

\section{PENDAHULUAN}

Menurut (Peraturan Menteri Kesehatan Republik Indonesia nomor 269/Menkes/Per/III/2008, 2008) yang dimaksud dengan rekam medis adalah berkas yang berisi catatan dan dokumen antara lain identitas pasien, hasil pemeriksaan, pengobatan yang telah diberikan, serta tindakan dan pelayanan lain yang telah diberikan kepada pasien. Sedangkan rekam merupakan berkas atau dokumen yang berisi catatan-catatan serta dokumendokumen mengenai identitas pasien, pemeriksaan, pengobatan, tindakan serta pelayanan lain yang telah diberikan kepada pasien serta berisi informasi lengkap mengenai data-data rekam medis pasien rawat jalan, rawat inap serta gawat darurat. Dari beberapa macam sistem pelayanan rekam medis tersebut sistem filing (penyimpanan) merupakan salah satu bagian yang sangat menunjang mutu pelayan kesehatan yang diberikan kepada pasien.
Menurut (Budi, 2011) beberapa fasilitas di ruang penyimpanan berkas rekam medis diantaranya ada (a) Ruang dengan suhu ideal untuk penyimpanan berkas agar berkas rekam medis tidak lembap, (b) Alat penyimpanan berkas rekam medis, bisa menggunakan Roll o pack, rak terbuka, dan filling cabinet (c) Tracer yang digunakan sebagai pengganti berkas rekam medis di rak filling yang dapat digunakan untuk menelusuri keberadaan rekam medis. Pentingnya tracer sebagai kartu pelacak berkas rekam medis keluar dari rak penyimpanan berkas rekam medis. Dengan adanya penyimpanan berkas rekam medis maka dapat memudahkan ditemukannya kembali berkas rekam medis pasien saat dibutuhkan.

Menurut (WHO, 2002) menggunakan sistem petunjuk keluar meningkatkan kerja instalasi rekam medis dan pengawasan rekam medis. petunjuk keluar atau tracer yaitu untuk memastikan bahwa bahwa rekam medis setiap kali akan dipindahkan dari penyimpanan 
untuk tujuan apapun, harus diganti dengan tracer, yang menunjukkan dimana rekam medis telah dikirim.

Menurut (Saputra \& Wagiran, 2020) Rancangan tracer yang terpilih setelah mempertimbangakan kelebihan-kelebihan dari bahan yang kuat dan tahan lama, warna yang mencolok serta berbeda dengan warna dari map berkas rekam medis di Puskesmas Tempunak, serta rancangan ini memiliki bentuk yang simpel dan mudah digunakan. Petunjuk keluar merupakan sarana penting dalam mengontrol penggunaan rekam medis. Biasanya digunakan untuk menggantikan rekam medis yang keluar dari penyimpanan.

Menurut (Huffman, 1994) Petunjuk keluar ini tetap berada di penyimpanan sampai rekam medis yang dipinjam dikembalikan dan disimpan kembali. Petunjuk keluar ini dilengkapi dengan kantong untuk menyimpan slip permintaan. Dari petunjuk keluar berwarna sangat membantu petugas dalam menandai lokasi yang benar untuk penyimpanan kembali rekam medis. petunjuk keluar dengan kantong plastik dapat digunakan untuk menjaga slip penyimpanan agar tidak hilang atau mengetahui keterlambatan laporan sampai rekam medis dikembalikan ke penyimpanan. Karena petunjuk keluar digunakan berulang-ulang, maka bahan yang kuat merupakan hal yang penting.

Menurut (Chamelia et al., 2019) di Puskesmas Kapas masih ditemukan adanya kesalahan letak (misfile) karena belum menggunakan tracer sebagai alat kendali untuk keluar dan masuknya berkas rekam medis pada rak penyimpanan dan dapat menghambat dalam penyediaan berkas rekam medis pasien serta menjadikan berkas rekam medis yang dicari tidak ditemukan atau tidak tersedia.

Berdasarkan penelitian terdahulu dapat disimpulkan bahwa tracer sebagai alat pengganti rekam medis atau pelacak masih belum diterapkan kendalanya antara lain ukuran tracer yang tidak sesuai standar ,bahan tracer yang mudah rusak, warna yang tidak mencolok membuat tracer menyebabkan misfile, informasi tracer yang tidak memadai serta kantong dan slip permintaan yang tidak terdapat pada tracer. Oleh karena itu perlu dilakukan penelitian dengan judul “ Literature Review Perancangan Tracer dalam Penyimpanan Dokumen Rekam Medis “

\section{METODE}

Penelitian ini menggunakan desain Literature Review penelitian yang mengkaji, meringkas dan menyimpulkan terkait perancangan tracer dalam penyimpanan dokumen rekam medis. Pencarian data tersebut menggunakan database Google Scholar. tersebut menggunakan database google scholar. Kata kunci yang digunakan dalam penelitian ini yaitu"Perancanggan tracer (outguide) rekam medis" OR "Desain tracer rekam medis". Dari hasil pencarian ditemukan sebanyak 28 artikel kemudian dipilih sebanyak 5 yang memenuhi kriteria inklusi yaitu diterbitkan dalam rentang tahun 2019-2020, rancangan penelitian menggunakan metode ceklist observasi dan pedoman wawancara, bahasa yang digunakan adalah Bahasa Indonesia.

\section{HASIL DAN PEMBAHASAN}

\section{A. Hasil}

1. Hasil Ekstraksi Data

Tabel 3.1

Hasil Ekstrasi Data

\begin{tabular}{|c|c|c|c|c|}
\hline $\begin{array}{l}\text { Author } \\
\text { (Tahun) }\end{array}$ & $\begin{array}{c}\text { Nama Jurnal, } \\
\text { Volume, No }\end{array}$ & Judul & Metode & Hasil \\
\hline $\begin{array}{l}\text { Difa Saputra, } \\
\text { Wangiran } \\
(2020)\end{array}$ & $\begin{array}{l}\text { JUPERMIK } \\
\text { Volume } 3 \text {, } \\
\text { Nomor } 2\end{array}$ & $\begin{array}{l}\text { Perancangan } \\
\text { tracer untuk } \\
\text { penyimpanan } \\
\text { dokumen rekam } \\
\text { medis di } \\
\text { Puskesmas }\end{array}$ & $\begin{array}{l}\text { Ceklist } \\
\text { observasi dan } \\
\text { pedoman } \\
\text { wawancara }\end{array}$ & $\begin{array}{l}\text { Rancanggan tracer dengan } \\
\text { ukuran } 35 \mathrm{~cm} \text { X } 10 \mathrm{~cm} \text { berbahan } \\
\text { dasar plastik Poly Ethyle } \\
\text { Terepthalate (PET) berwarna } \\
\text { merah yang mencantumkan } \\
\text { nomor rekam medis, nama } \\
\text { pasien, poli tujuan,peminjam dan } \\
\text { tanggal keluar disertai kantong } \\
\text { slip permintaaan }\end{array}$ \\
\hline $\begin{array}{l}\text { Siti Lailanda } \\
\text { Sindy, Rika } \\
\text { Yuanita } \\
\text { Pratama } \\
\text { (2019) }\end{array}$ & $\begin{array}{l}\text { JUPERMIK } \\
\text { Volume } 02 \text {, } \\
\text { Nomor } 02\end{array}$ & $\begin{array}{l}\text { Desain Tracer } \\
\text { (outguide) pada } \\
\text { ruang } \\
\text { penyimpanan } \\
\text { rekam medis di } \\
\text { Puskesmas } \\
\text { Sungai Durian } \\
\text { Sintang }\end{array}$ & $\begin{array}{l}\text { Observasi,wa } \\
\text { wancara dan } \\
\text { studi } \\
\text { dokumentasi }\end{array}$ & $\begin{array}{l}\text { Peneliti memilih desain alternatif } \\
1 \text { dengan ukuran } 30 \mathrm{~cm} \times 10 \mathrm{~cm} \\
\text { berbahan plastik poly ethyle } \\
\text { terephthalate } \\
\text { (PET) berwarna kuning dengan } \\
\text { mencantumkan nomor rekam } \\
\text { medis, nama pasien, poli } \\
\text { tujuan,tanggal masuk dan keluar } \\
\text { serta terdapat kantong untuk slip } \\
\text { permintaan }\end{array}$ \\
\hline
\end{tabular}




\begin{tabular}{|c|c|c|c|c|}
\hline $\begin{array}{l}\text { Author } \\
\text { (Tahun) }\end{array}$ & $\begin{array}{l}\text { Nama Jurnal, } \\
\text { Volume, No }\end{array}$ & Judul & Metode & Hasil \\
\hline $\begin{array}{l}\text { Nofri Heltiani, } \\
\text { Niska } \\
\text { Ramadhani } \\
(2021)\end{array}$ & $\begin{array}{l}\text { JMIKI } \\
\text { Volume 09, } \\
\text { Nomor } 01\end{array}$ & $\begin{array}{l}\text { Perancangan } \\
\text { dan prosedur } \\
\text { penggunaan out } \\
\text { guide pada } \\
\text { penyimpanan } \\
\text { berkas rekam } \\
\text { medis di Rumah } \\
\text { Sakit Rafflesia } \\
\text { Bengkulu }\end{array}$ & $\begin{array}{l}\text { Observasi } \\
\text { dan pedoman } \\
\text { wawancara }\end{array}$ & $\begin{array}{l}\text { Penulis merancang tracer } \\
\text { dengan ukuran } 25 \times 33 \mathrm{~cm} \\
\text { dengan bahan PVC (poly vhynil } \\
\text { chloride) berwarna biru yang } \\
\text { mencantumkan nomor rekam } \\
\text { medis, tanggal, ruanggan/poli, } \\
\text { loose sheet dan tanggal kembali } \\
\text { serta terdapat kantong loose } \\
\text { sheet dan memo. }\end{array}$ \\
\hline $\begin{array}{l}\text { Suhartinah, Tri } \\
\text { Murni, } \\
\text { M, Novia, J } \\
(2020)\end{array}$ & $\begin{array}{l}\text { JPKESMAS } \\
\text { Volume } 02 \text {, } \\
\text { Nomor } 01\end{array}$ & $\begin{array}{l}\text { Peningkatan } \\
\text { kerja bagian } \\
\text { penyimpanan } \\
\text { dokumen rekam } \\
\text { medis melalui } \\
\text { rancangan } \\
\text { tracer (outguie) } \\
\text { di Puskesmas } \\
\text { Gribig Kota } \\
\text { Malang }\end{array}$ & $\begin{array}{l}\text { Observasi } \\
\text { dan } \\
\text { wawancara }\end{array}$ & $\begin{array}{l}\text { Penulis mendesain tracer } \\
\text { dengan ukuran } 28 \mathrm{~cm} \times 6 \mathrm{~cm} \\
\text { berbahan kuat akrelik dan } \\
\text { sampul berbahan plastik tebal } \\
\text { yang tidak memiliki warna, } \\
\text { memuat data nomor rekam } \\
\text { medis, nama paien, tanggal } \\
\text { dipinjam, tanggal dikembalikan, } \\
\text { nama peminjam dan unit } \\
\text { pengguna, tanpa adanya kantong } \\
\text { dan slip permintaan }\end{array}$ \\
\hline $\begin{array}{l}\text { Luh Yulia } \\
\text { Adiningsih, } \\
\text { Komang } \\
\text { Ananta } \\
\text { Wijaya, Ida } \\
\text { Ayu Putu Feby } \\
\text { Paramita } \\
(2021)\end{array}$ & $\begin{array}{l}\text { JMIKI } \\
\text { Volume 09, } \\
\text { Nomor } 01\end{array}$ & $\begin{array}{l}\text { Perancangan } \\
\text { tracer untuk } \\
\text { mengendalikan } \\
\text { missfile berkas } \\
\text { rekam medis } \\
\text { pada bagian } \\
\text { filing di } \\
\text { Puskesmas I } \\
\text { Denpasar } \\
\text { Selatan }\end{array}$ & $\begin{array}{l}\text { Observasiona } \\
1 \text { dan } \\
\text { wawancara }\end{array}$ & $\begin{array}{l}\text { Rancangan } \text { tracer yang dipilih } \\
\text { yaitu alternatif III dengan ukuran } \\
23 \mathrm{~cm} \times 12.5 \mathrm{~cm} \text {, dari bahan } \\
\text { (plastik keras) infraboard } \\
\text { berwarna biru yang memuat } \\
\text { nomor rekam medis, nama } \\
\text { paien, ruangan peminjaman, } \\
\text { tanggal dipinjam, tanggal } \\
\text { dikembalikan, nama peminjam } \\
\text { dan keterangan disertai kantong } \\
\text { plastik sebagai tempat } \\
\text { menyisipkan form peminjaman. }\end{array}$ \\
\hline
\end{tabular}

2. Hasil Sintesis data

Berdasarkan hasil ekstrasi data, maka di temukan hasil sintesis sebagai berikut :
a. Mengetahui rancangan tracer berdasarkan aspek ukuran
b. Mengetahui rancangan tracer berdasarkan aspek bahan dan warna

\section{B. PEMBAHASAN}

1. Perancangan tracer dari aspek ukuran

Menurut (WHO, 2002) jenis tracer (petunjuk keluar) yang baik adalah bentuk kartu, biasanya ukuran sama atau sedikit lebih besar dari rekam medis. Pada jurnal menurut (Saputra \& Wagiran, 2020) ukuran tracer yaitu $35 \mathrm{~cm} \mathrm{X} 10 \mathrm{~cm}$ lebih besar dari map rekam medis; (Sindy \& Pratama, 2019) ukuran tracer $30 \mathrm{~cm} \times 10 \mathrm{~cm}$ lebih besar dari map rekam medis; (Heltiani \& Ramadani, 2021) ukuran tracer $25 \mathrm{~cm} \times 33 \mathrm{~cm}$,dengan ukuran lebar lebih besar dari rekam medis yaitu 34 x $24 \mathrm{~cm}$ dikarenakan map rekam medis diletakan secara horizontal; (Suhartinah et al., 2020) ukuran tracer $28 \mathrm{~cm} \mathrm{x} 6 \mathrm{~cm}$,dengan desain tracer pertama kali dipuskesmas tersebut; (Adiningsih et al., 2018) ukuran tracer $23 \mathrm{~cm}$ x $12.5 \mathrm{~cm}$ sesuai dengan ukuran rak

$$
\begin{aligned}
& \text { c. Mengetahui rancangan tracer } \\
& \text { berdasarkan aspek isi } \\
& \text { d. Mengetahui rancangan tracer } \\
& \text { menggunakan kantong dan slip } \\
& \text { permintaan }
\end{aligned}
$$

penyimpanan rekam medis di Puskesmas I Denpasar Selatan. Berdasarkan jurnal yang diteliti dapat disimpulkan sebagian besar ukuran tracer yang digunakan ukuranya sudah memenuhi standar yaitu berukuran sama atau lebih besar dari rekam medis yang terdapat di fasilitas kesehatan masing-masing.

2. Perancangan tracer dari aspek bahan dan warna

Menurut International Federation Health Organization (IFHRO), petunjuk keluar yaitu pengganti rekam medis yang akan dikeluarkan dari penyimpanan untuk tujuan apapun. Harus terbuat dari bahan yang kuat dan berwarna. Pada jurnal menurut (Saputra \& Wagiran, 2020) bahan tracer terbuat dari plastik poly ethyle terepthalate (PET) dengan warna merah; (Sindy \& Pratama, 2019) bahan 
(Heltiani \& Ramadani, 2021) bahan tracer terbuat dari PVC (poly vhynil chloride) berwarna biru; (Suhartinah et al., 2020) tracer terbuat dari bahan kuat akrelik dan sampul berbahan plastik tebal tidak berwarna; (Adiningsih et al., 2018) tracer terbuat dari bahan (plastik keras) infraboard berwarna biru. Berdasarkan jurnal yang diteliti dapat disimpulkan bahan yang digunakan sudah sesuai standar yaitu bahan kuat dimana terdapat persamaan bahan oleh (Saputra \& Wagiran, 2020) dan (Sindy \& Pratama, 2019) menggunakan plastik poly ethyle terepthalate (PET) dan berwarna yang mencolok(warna terang), namun masih terdapat desain tracer Suhartinah et al., (2020) yang tidak berwarna.

\section{Perancangan tracer dari aspek isi}

Menurut (WHO, 2002) jenis tracer (petunjuk keluar) yang baik adalah bentuk kartu, biasanya ukuran sama atau sedikit lebih besar dari rekam medis dan harus tercantum nama pasien,nomor rekam medis,tujuan rekam medis atau peminjam dan tanggal keluar. Pada jurnal menurut (Saputra \& Wagiran, 2020) tracer memuat isi berupa nomor rekam medis, nama pasien, poli tujuan, peminjam dan tanggal keluar; (Sindy \& Pratama, 2019) tracer memuat isi berupa nomor rekam medis, nama pasien, poli tujuan,tanggal masuk dan keluar; (Heltiani \& Ramadani, 2021) tracer memuat isi berupa nomor rekam medis, tanggal, ruanggan/poli, loose sheet dan tanggal kembali; (Suhartinah et al., 2020) tracer memuat isi berupa nomor rekam medis, nama paien, tanggal dipinjam, tanggal dikembalikan, nama peminjam dan unit pengguna; (Adiningsih et al., 2018) tracer memuat isi berupa nomor rekam medis, nama paien,ruangan peminjaman,tanggal dipinjam,tanggal dikembalikan, nama peminjam dan keterangan. Berdasarkan jurnal yang diteliti semuanya sudah sesuaii standar karena memuat antara lain nama pasien,nomor rekam medis,tujuan rekam medis atau peminjam dan tanggal keluar.

4. Perancangan tracer menggunakan kantong dan slip permintaan

Menurut (Huffman, 1994) Petunjuk keluar ini tetap berada di penyimpanan sampai rekam medis yang dipinjam dikembalikan dan disimpan kembali. Petunjuk keluar ini dilengkapi dengan kantong untuk menyimpan slip permintaan. Pada jurnal menurut (Saputra \& Wagiran, 2020) desain tracer terdapat kantong slip permintaaan berukuran $8 \mathrm{~cm} \mathrm{x} 11$ $\mathrm{cm}$ dan berwarna merah; Sindy \& Pratama, (2019) desain tracer terdapat kantong untuk
(Suhartinah et al., 2020) desain tracer tidat terdapat kantong maupun slip permintaan; (Adiningsih et al., 2018) desain tracer terdapat kantong plastik sebagai tempat menyisipkan form peminjaman.Berdasarkan jurnal yang diteliti sebagian besar sudah menggunakan kantong untuk menyimpan slip permintaan, dimana fungsinya untuk memudahkan dalam peminjamaan maupun melacak dokumen rekam medis,namun masih terdapat desain tracer Suhartinah et al., (2020) yang tidak menggunakan kantong dan slip permintaan.

\section{SIMPULAN}

1. diteliti dapat disimpulkan sebagian besar ukuran tracer yang digunakan ukuranya sudah memenuhi standar yaitu berukuran sama atau lebih besar dari rekam medis yang terdapat di fasilitas kesehatan masing-masing.

2. Berdasarkan jurnal yang diteliti dapat disimpulkan bahan yang digunakan sudah sesuai standar yaitu bahan kuat dan berwarna yang mencolok(warna terang), namun masih terdapat desain tracer Suhartinah et al., (2020) yang tidak berwarna.

3. Berdasarkan jurnal yang diteliti semuanya sudah sesuai karena mememuat antara lain nama pasien,nomor rekam medis,tujuan rekam medis atau peminjam dan tanggal keluar.

4. Berdasarkan jurnal yang diteliti sebagian besar sudah menggunakan kantong untuk menyimpan slip permintaan, dimana fungsinya untuk memudahkan dalam peminjamaan maupun melacak dokumen rekam medis,namun masih terdapat desain tracer Suhartinah et al., (2020) yang tidak menggunakan kantong dan slip permintaan.

Berdasarkan simpulan diatas, saran yang diberikan yaitu: an tracer dari aspek warna sebaiknya di Puskesmas Gribig Kota Malang menerapkan tracer dengan warna yang mencolok agar dalam pencariannya mudah.

2. Berdasarkan jurnal yang dibaca rancangan tracer dari aspek kantong dan slip permintaan sebaiknya di Puskesmas Gribig Kota Malang menerapkan kantong dan slip permintaan sesuai standar yang berlaku

\section{DAFTAR PUSTAKA}

Adiningsih, L. Y., Wijaya, K. A., Ayu, I., \& Feby, P. (2018). Perancangan Tracer untuk Mengendalikan Missfile Berkas Rekam Medis pada Bagian Filing di Puskesmas I Denpasar Selatan. Jurnal Manajemen Informasi Kesehatan Indonesia, 09(01), 11-17. 
Chamelia, R., Sudalhar, \& Pratama, tegar wahyu yudha. (2019). Pengaruh Design Tracer Terhadap Penyimpanan Berkas Rekam Medis Rawat Jalan Di Puskesmas Kapas. Jurnal Hospital Science, 03(02), 34-40.

Heltiani, N., \& Ramadani, N. (2021). Perancangan dan Prosedur Penggunaan Out Guide pada Penyimpanan Berkas Rekam Medis di Rumah Sakit Rafflesia Bengkulu. Jurnal Manajemen Informasi Kesehatan Indonesia, 09(01), 34-39.

Huffman, E. k. (1994). Health Information Management.

International Federation Health Organization (IFHRO). (2006). Education Module For Health Record Practice.

Peraturan Menteri Kesehatan Republik Indonesia nomor 269/Menkes/Per/III/2008. (2008). Rekam Medis.

Saputra, D., \& Wagiran. (2020). Perancangan Tracer untuk enyimpanan Dokumen Rekam Medis di Puskesmas. Jurnal Perekam Medis Dan Informasi Kesehatan, 3(02), 69-73.

Sindy, lailanda siti, \& Pratama, rika yuanita. (2019). Desain tracer (outguide) pada Ruang Penyimpanan Rekam Medis di Puskesmas Sungai Durian Sintang. Jurnal Perekam Medis Dan Informasi Kesehatan, 2(02), 54-62.

Suhartinah, Murni, T., Novia, J, \& M. (2020). Peningkatan Kerja Bagian Penyimpanan Dokumen Rekam Medis melalui Rancangan Tracer (outguide) di Puskesmas Gribig Kota Malang. Jurnal Pengabdian Masyarakat, 02(01).

World Health Organization. (2002). Manual Medical Record. Geneva. 